\title{
Un vaso cultual hallado en Ampurias
}

\author{
SYLVIA RIPOLL LOPEZ *
}

Durante la campaña de excavaciones de 1967 en la ciudad romana de Ampurias, bajo la dirección de $\mathrm{E}$. Ripoll y en colaboración con $\mathrm{M}$. Llongueras, se excavó un silo en una estancia situada al Este del foro ampuritano, en la parte oriental del kardo B, en una zona llamada "Campo Ramis». El vaciado del silo, que está excavado en la roca, se realizó por niveles teóricos de $20 \mathrm{~cm}$. de espesor. La cavidad contenía una gran cantidad de material cerámico, alrededor de los 18.000 fragmentos. Una vez finalizada la excavación del silo, se llegó a la conclusión de que su contenido era heterogéneo y que fue utilizado como escombrera durante un largo período de tiempo; por los materiales en él hallados se deduce que éste dejó de llenarse a finales del siglo II o principios del siglo III d.C. '. Según el estudio de A. López Mullor de la cerámica de paredes finas del silo, el terminus ante quem de éste sería el de finales del siglo I d.C. ${ }^{2}$. El origen del silo, así como el de los otros depósitos de la zona del foro, es incierto. Dos son las hipótesis: la una dice que estos podrían haber estado ya en funcionamiento en una fecha anterior al

* Universidad Complutense. Madrid.-Nuestro padre, Eduardo Ripoll, interesado por la problemática de los posibles cultos orientales en Ampurias, hizo que fijáramos nuestra atención en este vaso. Quisiéramos agradecer al Prof. Paolo Scarpi del «Istituto de Filologia Greca" de la Universidad de Padua, la lectura del manuscrito y sus interesantes consejos.

J. M. NOLLA, "Las ánforas romanas de Ampurias", Ampurias, 36-37, 1974-75, pág. 166, da esta cronologia, del momento de abandono del silo como escombrera, basándose en la presencia de "sigillata" clara, pero sin especificar los tipos aparecidos. El silo contenía, además, cerámica campaniense $A$ tardia y $B$, asi como todos los tipos de terra sigillata.

2 A. LOPEZ MULLOR, Las cerámicas romanas de paredes finas en Cataluña, Tesis doctoral inédita, UNED, 1987, vol. I, pág. 119. 
siglo ॥ a.C. y que por lo tanto serian indígenas ${ }^{3}$, la otra, los pone en relación con el llamado praesidium militar de época de Catón ${ }^{4}$.

Entre los diversos materiales aparecidos en este silo, se halló un vaso, roto en varios fragmentos, con una decoración exterior aplicada, que por los motivos representados merece una atención especial (figs. 1 y 2).

Es un vaso de forma globular, con el borde vuelto hacia fuera, de base plana, con cuello largo y dos asas, de las cuales sólo se conserva su arranque inferior. Las dimensiones del mismo son: $\mathrm{h}=19,5 \mathrm{~cm}$.; $\varnothing$ de la boca $=18,5 \mathrm{~cm}$; $\varnothing$ de la base $=14,5 \mathrm{~cm}$.; espesor de las paredes $=1 \mathrm{~cm}$. La pasta es de un color marronáceo-gris. La decoración está realizada con la técnica de aplicación de cordones y pastillas antes de la cocción ${ }^{5}$. El vaso, por sus características, seria de producción local.

Las dos caras del vaso presentan la misma composición, y las diferencias entre ellas son mínimas ${ }^{6}$. El vaso se halla rodeado, a media altura y en toda su longitud, por un cordón que parte del arranque del asa izquierda de la cara $A$, donde también termina remontando el cuello (en este punto está roto). Este cordón, que podría simbolizar una serpiente, enmarca toda la decoración, constituida por cuatro elementos más, y que se desarrolla en la zona del cuello. Una lagartija o salamandra se dispone horizontalmente, con la cabeza orientada hacia la derecha (en la cara B este animal es un poco más pequeño). Encima de la sala-

${ }^{3}$ A. LOPEz Mullor, Las cerámicas... op. cit,, vol. I, págs. 118-119. Para este autor, el hecho de que los silos estén excavados en la roca, hace difícil establecer una época de fundación. Supone que todos fueron construidos durante el mismo periodo y el hecho de que algunos de ellos cayeran en desuso a finales del siglo I a.C., le hace pensar que su construcción sea anterior y que perteneciesen a los indigenas que se agruparon dentro del campamento fijo construido por Catón y cuyos límites eran los de la ciudad romana actual. M. J. Pena, en un seminario realizado en la Universidad de Besançon (21 de noviembre de 1988) sobre el territorio de Ampurias, apuntó también la posibilidad de que estos silos hubiesen pertenecido a los indígenas, pues ninguna villa romana del territorio ampuritano posee silos. Ésta, cree también posible que la primitiva ciudad romana de Ampurias fuese la ciudad indigena de "Untikesken". Acerca del problema del llamado praesidium militar se puede consultar E. RIPOLL Els origens de la ciutat romana d'Empúries, Reial Acadèmia de Bones Lletres de Barcelona, Barcelona 1978, págs. 48-49.

${ }^{4} \mathrm{~J}$. AQUILUE et alii, El forum romà d'Empúries, Monografies Emporitanes, VI, Barcelona 1984 , p. 47.

${ }^{5}$ Esta es una técnica muy elemental utilizada en alfarería, que todavía hoy se emplea para realizar vasos de fantasía, como por ejemplo los "cantirs" o botijos de Vilafranca del Penedés o los aguamaniles de Reus.

6 Estas dos caras las hemos denominado A y B. La descripción del vaso la realizamos a partir de la cara $A$, señalando al mismo tiempo las pequeñas diferencias que presenta la B. 

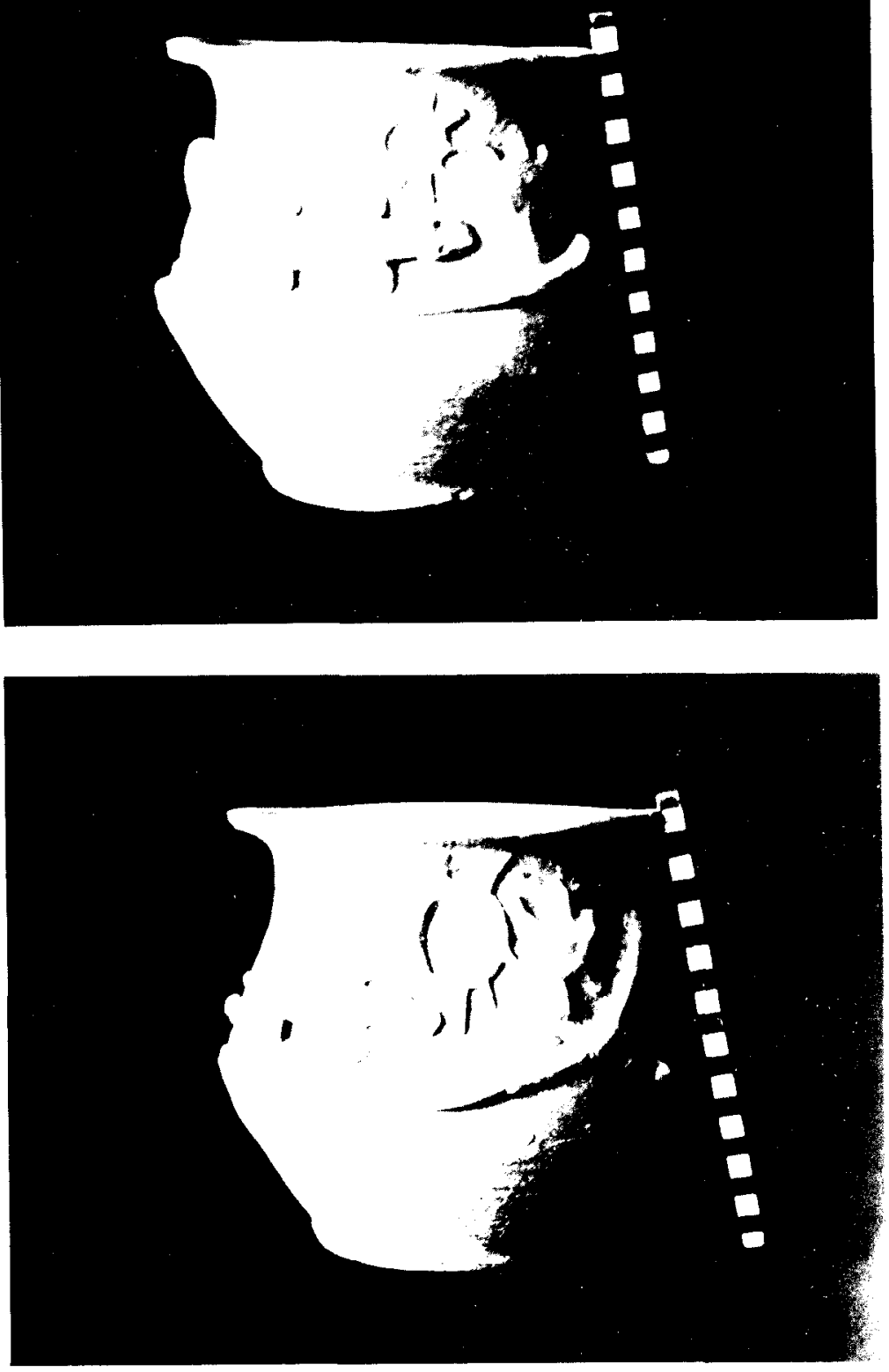

Figs. 1 y 2. Vaso cultual procedente de Ampurias; Museo Monográfico de Ampurias; 1) cara $A$; 2) cara $B$. 
mandra, un semicírculo abierto hacía abajo, que sin lugar a dudas representa un creciente lunar (en la cara B su disposición es la misma). A la derecha de éste y por encima de la cabeza de la salamandra, se sitúa un círculo del que penden nueve rayos, que representaría un sol (en la cara $\mathrm{B}$ el círculo es más grande y de él penden ocho rayos). A la derecha de esta última figura, se halla un sapo o una rana, con la cabeza orientada hacia la derecha (en la cara B esta figura es algo mayor).

Esta decoración plantea un problema de función y de atribución, que intentaremos dilucidar a continuación, a través del simbolismo de las figuras, sin olvidar que todo símbolo es verdadero en tanto que haz de significaciones y que no es lícito reducirlo a una de sus valencias ${ }^{7}$.

Según Plinio ( $X, 188)$, la salamandra, que tiene la forma de una lagartija y el cuerpo salpicado de estrellas, es un animal que sólo aparece en la época de las grandes lluvias, es tan frío que apaga el fuego como lo haría el hielo y el líquido blanco que sale de su boca hace que caigan los pelos del cuerpo humano, allí donde lo toca, quedando sobre la piel una señal blanca. Así pues, los dos puntos más importantes de la salamandra para los antiguos eran: su inmunidad ante el fuego y su venenosidad $^{8}$. Se pensaba que podía matar a varias personas a la vez, y que los hombres por ella heridos morían de remordimiento y no eran aceptados por la tierra ${ }^{9}$. La salamandra, por sus propiedades, era utilizada en rituales mágicos ${ }^{10}$. Se halla representada entre los símbolos del

7. ElIADE, Mefistofeles y el andrógino, Madrid, 1969, pág. 263. Al hacer el análisis simbólico de estas representaciones, las pondremos también en relación con la magia, los ritos agrarios romanos y los cultos mistéricos, y en especial con el culto a Sabazios. Sabazios es una divinidad tracia que podría haber correspondido al dios solar; él es un dueño del destino y fuente de todas las bienaventuranzas. La religión de Sabazios tenía un pecado original, una purificación que borraba el pecado de la carne y un juicio postrimero, seguido de un paraíso. Sus misterios alcanzaron un gran auge en epoca helenística y aparece ya en Roma en el siglo ॥ a.C., extendiéndose después por todo el Imperio romano. Sobre este dios se puede consultar la siguiente bibliografía: H. SCHAEFER, Sabazios, RE, IA 2, 1920, col. 1540-1551; S. E. JoHNSON, The present state of Sabazios research, ANRW, 17-3, 1984, págs. 1583-1613; C. PICARD, Sabazios dieu thraco-phrygien: expansion et aspects nouveaux de son culte, Revue Archéologique, II, 1961, págs. 129-176; E. Lozovan, Sabazios et la benedictio latina, Oikoumene, Studi paleocristiani in onore del Concilio Ecumenico Vaticano II. Catania, 1964, págs. 181-191; F. Cumont, Les mystères de Sabazios et le Judaïsme, Compte Rendus de l'Académie des Inscriptions et Belles Lettres, Paris, 1906, págs. 63-79; I. P. Culianu y G. PoghiRc, Sabazios, The Encyclopedia of Religion, dirigida por M. Eliade, Londres 1987, vol. 12, págs. 499-500.

${ }^{8}$ O. Keller, Die antike Tierwelt, vol. II, Hildesheim, 1980 (Leipzig 1913), pág. 319.

${ }^{9}$ Plinio, XXIX, 74-75.

${ }^{10}$ Plinio XXIX, 76. La piel de la salamandra era utilizada como antídoto contra las quemaduras y se decía que ciertas partes del animal conservadas en miel abrían el apetito sexual. 
culto a Mitra y en el de Sabazios ". Es en las provincias del Norte del Imperio romano, Germania y Helvetia, donde se han encontrado más representaciones de salamandras ${ }^{12}$.

Desde un punto de vista histórico cultural el sapo es venenoso y la rana inofensiva. Para los pueblos antiguos el sapo pertenecía al grupo de los animales que habitaban el mundo subterráneo. La farmacopea consideraba el veneno del sapo muy poderoso, por ser éste un animal nocturno. Son muchos los ejemplos en los que su veneno y su cuerpo son utilizados en brebajes mágicos ${ }^{13}$. Para los agricultores romanos los sapos eran una peste, y para evitarlos daban por la noche una vuelta al campo con un sapo dentro de un recipiente, que luego enterraban en el centro de éste ${ }^{14}$. Este animal, al igual que la salamandra, se halla entre los símbolos del culto a Sabazios ${ }^{15}$.

La serpiente juega en casi todos los pueblos de la antigüedad un papel muy importante, pues sus movimientos sinuosos y su poder mortifero sugieren la presencia misteriosa del mal. Pero también tiene, como por ejemplo entre los romanos, un papel protector de la casa y de la fecundidad ${ }^{16}$. Este reptil tiene un significado chthónico y juega un papel

${ }^{11}$ En el culto a Sabazios se encuentran representadas salamandras en las manos votivas; ejemplos entre otros son: la del Musée Romain de Avenches (Suiza) ( $n{ }^{\circ}$ inv. 447; Bronzes romaines de Suisse, Catálogo de la exposición, Lausanne, 1978, pág. 51) y las dos del Museo Romano de Brescia (O. lanovitz, I culto solare nella "X Regio", Milán, 1972, págs. 98-99). La salamandra se halla también representada sobre las placas de bronce relacionadas con este culto; sobre ello se puede consultar el artículo de A. García Y BELLIDO, Una deidad oriental en la España romana. El culto a Sabazios, Revista de la Universidad de Madrid, I, 1952, págs. 345-361, sobre una de estas placas hallada en Ampurias, donde da una abundante bibliografia sobre el tema.

12 I. ORTH, Salamander, RE, I A 2, 1920, col. 1821-1822.

${ }^{13}$ Plinio (XXXII, 139) dice que para despertar el amor hay que atar ancas de sapo al brazo derecho y para matarlo hay que colgarse un sapo. Contra la sarna se recomendaba la lengua de sapo y el caldo de su cocción (Plinio, XXVIII, 117). Era también utilizado como antidoto contra la mordedura de serpiente (Plinio XXXII, 48) y de la salamandra. Sobre la utilización del sapo y de la rana en la farmacología antigua ver: O. KELLER, Die autike..., op. cit, vol. Il, págs. 305 y 306 y M. WELLMANN, Frosch, RE, VII 2, 1910, col. 113-119.

14 O. Keller, Die antike... op. cit., vol. II, pág. 307. En algunas tumbas de Renania, datadas entre los siglos $\|$-iv d.C., aparecieron varios modelos de instrumental agricola y de animales, entre ellos sapos y salamandras. La mayor parte de los investigadores los han puesto en relación con el culto a Sabazios, pero J. KOLENDO (L'agricoltura nell'talia romana, Rcma, 1980, Apéndice III: Modellini di erpice trovati in Renania, págs. 213-218) los atribuye a creencias agrícolas locales.

${ }^{15}$ Véase nota $n^{\circ} 11$, pues el sapo ó la rana aparecen también representados en las manos votivas y en las placas del culto a Sabazios.

${ }^{16}$ S. G. F. Brandon, Diccionario de religiones comparadas, Madrid, 1975, vol. II, pág. 1310 (serpiente). O. KELLER. Die antike... op. cit., vol. II, págs 285-286. H. Gossen y A. 
muy importante en los misterios griegos, como por ejemplo en los dedicados a Dionysos, divinidad a la que era asimilado frecuentemente Sabazios ${ }^{17}$. La serpiente es el símbolo de muchas divinidades: Apolo, Esculapio, Serapis ${ }^{18}$, Mitra, Sabazios ${ }^{19}$, etc. En el mundo de la magia la serpiente aparece en numerosas prácticas, partes de ella son llevadas como amuleto y su veneno es utilizado con fines mortíferos y como antídoto en la medicina ${ }^{20}$.

El sol no es sólo el astro que ilumina y calienta, es también la proyección de un conjunto de experiencias unidas a la luminosidad, al calor, a la periodicidad, a la desaparición y al retorno, a la fecundidad, etc. Es frecuentemente considerado como el ojo de un ser celestial, pero también tiene un simbolismo nocturno, malo y funerario ${ }^{21}$. Helios, el sol, es invocado en los papiros mágicos como el dios de la unión, pues es considerado, el señor del cielo, el árbitro de la fortuna y el guía de las cosas divinas y humanas. El sol y la luna son considerados como los padres de los magos, y así el sol, purificador, protege al mago de los demonios malignos ${ }^{22}$.

La luna, por pertenecer al mundo de la noche, está unida a la tierra y al mundo de ultratumba. Selene, la hermana, la amante y la hija del sol, se convierte con el sincretismo en diosa del destino, de la luz y del

StEIER, Schiange, RE, II A 1, 1921, col. 494-557. M. LURKER, Snakes, The Encyclopedia of Religion, dirigida por M. Eliade, Londres, 1987, vol. 13, págs. 370-374.

17 En los misterios dedicados a Sabazios se simulaba la unión mística del iniciado con el dios, dejando deslizar las mujeres bajo sus ropajes una serpiente verdadera o de oro, simbolizando ésta el propio dios y a su poder fecundante (Clemente de Alejandria, Protr. II, 16; Arnobius, Adv. nat. V, 21; Firmicus Maternus, De err. pot. rel., 10).

${ }_{18}$ La serpiente en Esculapio y Serapis tiene un significado de vida y salud.

${ }_{19}$ Muchos vasos con representaciones de serpientes que apoyan sus cabezas sobre el borde del vaso son atribuidos al culto de Mitra, como por ejemplo los expuestos en las vitrinas sobre religión romana del Römisch-Germanischen Museum de Colonia ( $\boldsymbol{n}{ }^{.0 s}$ inv. $3781 ; 58,289 ; 58,220$ ), los del Rheinisches Landesmuseum de Bonn, o el del Bernisches Historiches Museum ( $n .^{\circ}$ inv. 19.287). Sobre las representaciones de serpientes en las manos votivas y en las placas del culto a Sabazios, ver nota $n .{ }^{\circ} 11$.

${ }^{20}$ Plinio, XX, 40, 45, 95, 195; XXII, 18, 31; XXIX, 65.

2) M. ElIADE, Imágenes y simbolos, Madrid, 1974, pág. 190. O. Jessen, Helios, RE, VIII 1, 1912, col. 58-92. Tanto el sol como la luna, por ser signos celestes, están en relación con Sabazios; el sol indicaria su poder sobrenatural y luminoso y la luna su poder protector. Esto sucede también en otros cultos orientales, singularmente en el de Mitra, cuyo carácter astrológico es una de sus bases.

${ }^{22}$ M. P. NiLsoN, Die Religion in den Griechischen Zauberpapyri, Bulletin de la Société Royale des Lettes de Lund, II, 1947-48, págs. 77-79. Secundariamente se puede consultar también, J. ANNEQUIN, Recherches sur laction magique et ses representations (ler et lleme siècles après J.C.), Les Belles Lettres, Paris, 1973, págs. 20 y 55 (sobre la gran frecuencia con que es mencionado Helios en los papiros mágicos ver cuadro XII, pág. 170). 
cielo. Esta diosa tiene en el culto de Mitra un papel relevante ${ }^{23}$. Apuleyo, cuya filosofía reposa en la simpatía universal, considera a la luna diosa soberana y que todo en el mundo subsiste y está regido por la divina influencia de su luz y de sus poderes ${ }^{24}$. La luna es vista como la protectora de la magia, ya que los actos mágicos tienen lugar por la noche $y$ Hécate, la reina de la magia, la mediadora divina de las fuerzas del cosmos, es asociada a la luna ${ }^{25}$.

Hasta el momento, sólo hemos localizado un paralelo para nuestro vaso, éste se encuentra en el Römisch-Germanischen Zentralmuseum de Mainz (fig. 3) y procede de Túne ${ }^{26}$. Es también un vaso de producción local, profusamente decorado, sobre el que aparecen representadas numerosas figuras que se distribuyen en dos registros enmarcados por serpientes: a) una rana, una salamandra, un hombre sosteniendo un bipenne; b) un toro, una figura femenina con un niño en brazos, un ara con una cabeza de carnero, etc. Por los elementos representados pensamos que puede estar en relación con un culto mistérico y en especial con el de Sabazios ${ }^{27}$.

Por lo dicho hasta este punto vemos que las figuras representadas sobre el vaso de Ampurias pueden ser puestas en relación tanto con la magia, como con los cultos mistéricos y especialmente con el de Sabazios, asi como con ritos agrarios.

¿Pero cuales son los límites entre la magia y la religión? Atribuir el vaso al culto de Sabazios es una tentación, por haberse hallado en Ampurias una placa argentea dedicada a este dios ${ }^{28}$, pero tal vez sea querer forzar demasiado el simbolismo de las figuras al ponerlas en relación

23 W. Grundel, Mond., RE, XXXI, 1933, col. 76-105. F. SCHWEnN, Selene, RE II A 1 1921, col. 1136-1144.

24 Apuleyo, Metamor. XI, I.

25 J. ANNEQUIN, Recherches ... op. cit., pág. 83.

${ }^{26} \mathrm{~N}^{\circ}$ inv. O.39627. La altura del vaso es de $29 \mathrm{~cm}$. Hasta el momento no ha sido ni estudiado ni publicado

${ }_{27}$ Esta atribución la basamos en la placa del culto a Sabazios de Ampurias (A. GaRcla y BELLIDO, Una dejdad oriental ... op. cit. figs. 1 y 2) sobre la que todos los elementos del vaso se hallan representados.

${ }^{28}$ La bibliografía sobre esta placa es: A. GARCIA y BELLIDO, Una deidad oriental ... op cit; idem., Les religions orientales dans l'Espagne romaine, Leiden, 1967, cap. VIII Sabazios, págs. 73-81; M. Almagro, Manifestaciones del culto de Zeus Serapis y de Sabazios en España, Cuadernos de Trabajos de la Esc. Esp. de H. ${ }^{2}$ y Arq. en Roma, VIII, 1956, págs. 199-212. Para Garcia y Bellido estas placas no pueden ser posteriores al siglo 10 III d.C. y según M. Oliva Prat (Urnas cinerarias de plomo de Ampurias, Memorias de los Museos Arqueológicos Provinciales, IX-X, 1948-49, pág. 282) dataría, por la urna, del siglo d.C. 


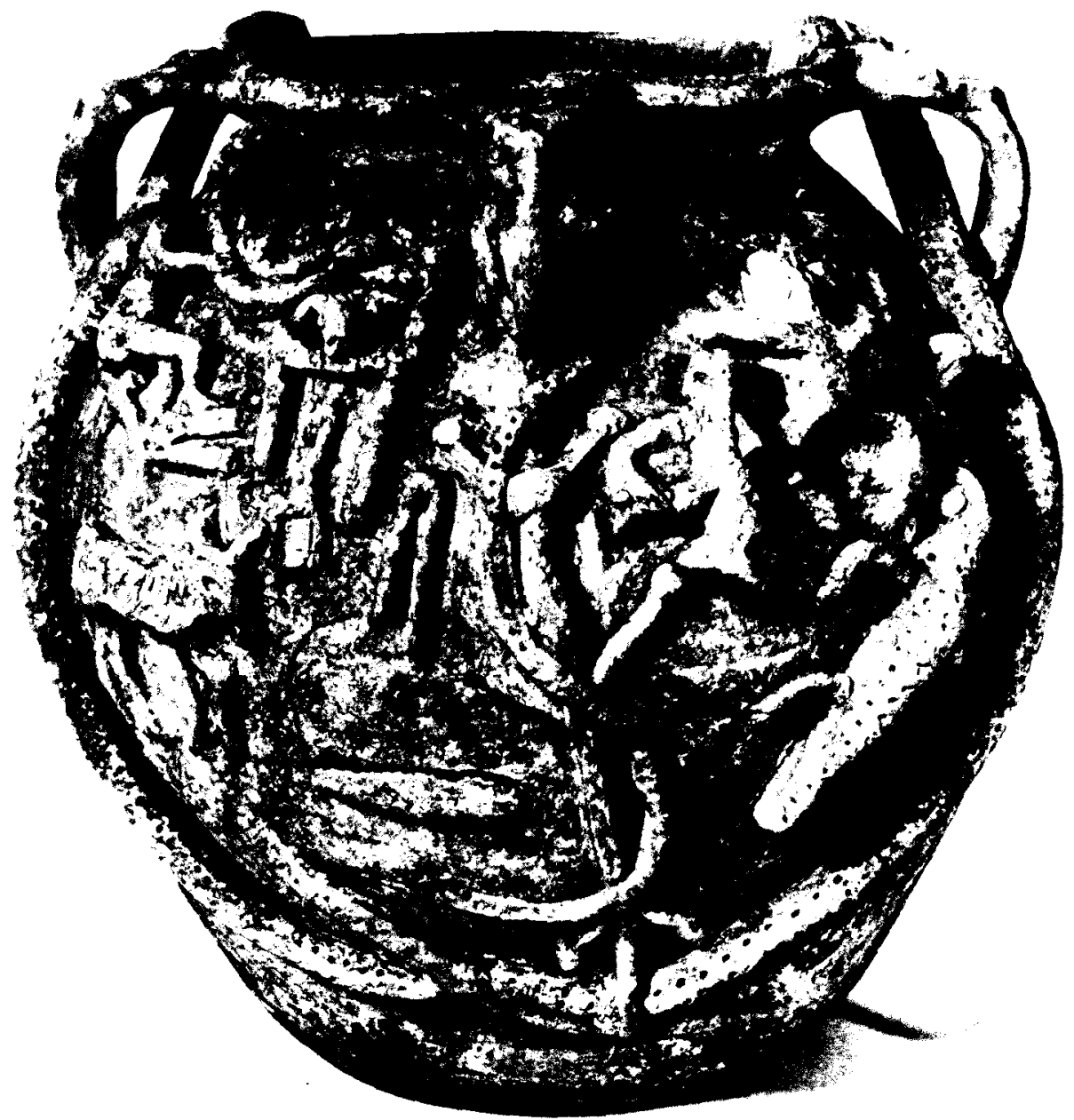

Fig. 3. Vaso cultural del Römisch-Germanischen Zentralmuseum de Mainz, procedente de Túnez.

con algún ritual de su culto. Considerarlo como un vaso perteneciente a un rito agrario, es también arriesgado, pues las usanzas entre los pueblos son muy diversas. Lo más fácil seria atribuirlo al mundo de la magia, 
pues ésta, como dice Plinio, es una mezcla de medicina, religión y astrología y el arte que mayor poder tiene sobre la tierra ${ }^{29}$.

Por tanto, ante la duda y la dificultad de darle una atribución precisa, creemos que debemos limitarnos a considerarlo como un vaso cultual, ya que bajo cultual se sobrentiende tanto una función mágica como religiosa. Por otra parte, es difícil darle una cronología precisa, pues por el lugar del hallazgo y por su contexto arqueológico debemos situarlo entre el siglo I y principios del siglo III d.C.

29 Plinio $X X X, 1$ 1-2 A. Ermout, La magie chez Pline l'Ancien, Hommages à Jean Bayet, Latomus, LXX, 1964, págs 190-195). Sobre la magia en general, ver entre otros: M. Mauss, Teoria generale della magia e altri saggi, Ed. G. Inaudi. Turin, 1965 (ed. francesa, 1950), págs. 5-152; H. Hubert, Magia, Darg. et. Sag., III B, Paris, 1904, págs 1494-1521; J. ANNEQUIN, Recherches ... op. cit., donde se puede encontrar una vasta bibliografia sobre el tema. 